\title{
Current aspects on the management of viral uveitis in immunocompetent individuals
}

\author{
This article was published in the following Dove Press journal: \\ Clinical Ophthalmology \\ 5 June 2015 \\ Number of times this article has been viewed
}

\author{
Uwe Pleyer' \\ Soon-Phaik Chee ${ }^{1-5}$ \\ 'Augenklinik, Charité- \\ Universitätsmedizin Berlin, \\ Campus Virchow-Klinikum, Berlin, \\ Germany; ${ }^{2}$ Ocular Inflammation \\ and Immunology Service, Singapore \\ National Eye Centre, ${ }^{3}$ Singapore Eye \\ Research Institute, ${ }^{4}$ Department of \\ Ophthalmology, Yong Loo Lin School \\ of Medicine, National University \\ of Singapore, ${ }^{5}$ Duke-NUS Graduate \\ Medical School Singapore, Singapore
}

\begin{abstract}
Viruses are a fundamental etiology of ocular inflammation, which may affect all structures of the organ. Advances in molecular diagnostics reveal an increasingly broader spectrum of virus-associated intraocular inflammation, including all members of the herpes family, rubella virus, and other more rare causes such as Epstein-Barr and chikungunya virus. In particular, viruses of the herpes family are important causes of anterior and posterior uveitis. Owing to their often fulminant clinical course and persistence in ocular tissues, a clear differential diagnosis between alpha- and beta-type herpes viruses is essential to guide acute and long-term treatment. Here, we review the epidemiology, clinical, and laboratory findings of virus-associated uveitis with emphasis on their therapy and management and include our own experience.
\end{abstract}

Keywords: clinical trials, cytomegalovirus, herpes virus, infection, inflammation, treatment, uveitis

\section{Introduction}

Human beings are a natural reservoir for a number of viruses. This may explain the fundamental role of these infectious agents in several diseases, including uveitis. Worldwide, a high seroprevalence of viral infections can be observed. It is beyond the scope of this article to describe all viral infections with intraocular manifestations. Instead, the goal of this article is to highlight viral infections that are most common and relevant for the ophthalmologist. This includes in particular rubella virus, herpes simplex virus (HSV), varicella-zoster virus (VZV), and cytomegalovirus (CMV).

Many viruses share in common a lifelong persistence of their genome in infected tissues and the risk of reactivation. Asymptomatic virus shedding occurs in immunocompetent individuals with variable frequencies depending on the specific virus and host factors such as age and prior symptomatic disease. Interestingly, there are distinct genotypes of each of these viruses that can be differentiated. A finding may have clinical implications, since reinfection with different strains might be possible and resistance to commonly used antivirals may occur. ${ }^{1,2}$ Infection in the immunocompetent host results in lifelong immunity in the majority of individuals. However, individuals with immature or diminished immune function, eg, infants and the elderly, are at particular risk of acute infection and recurrence. The humoral immune response based on virus-specific antibodies is an important defense mechanism, but does not seem to be essential for recovery from herpes virus infection. Acute control of infection is mainly dependent on virus-specific T lymphocytes, which eliminate intracellular pathogens. The activity of these lymphocytes may temporarily diminish or even disappear from patients in the acute phase disease and is restored during convalescence. Both virus-induced cytopathology and the subsequent inflammatory response are responsible for ocular damage.
Department of Ophthalmology, Charité Universitätsmedizin Berlin, Campus Virchow-Klinikum, Augustenburger Platz I, I 3353 Berlin, Germany

Tel +493045065 4l 3l

Fax +49 30450554900

Email uwe.pleyer@charite.de 


\section{Herpes virus-associated anterior uveitis}

Although a large proportion of anterior uveitis is noninfectious and associated with the HLA-B27 haplotype, viruses are regarded as an important cause of infectious anterior uveitis. Half of the human herpes viruses, which belong to the Herpesviridae family, are known to cause anterior uveitis. These include HSV,${ }^{1-3} \mathrm{VZV}$, and CMV. Other than rubella virus, other rare causes include Epstein-Barr virus, human parvovirus, and chikungunya virus. ${ }^{4-10}$

\section{Epidemiology}

\section{Herpes simplex virus}

The HSV infection is transmitted by direct skin-to-skin contact. It lies latent within the fifth cranial nerve sensory ganglion and reactivates from time to time, causing recurrent disease. HSV infection may manifest initially in the periocular skin and cornea or may present solely as an acute anterior uveitis in the fourth and fifth decades of life. Both sexes are equally affected. ${ }^{11}$

\section{Varicella-zoster virus}

Primary VZV infection is a blistering febrile illness following which the virus lies dormant in the neural sensory ganglia. VZV anterior uveitis may manifest during the sixth or seventh decades of life following reactivation of the virus in the ophthalmic division of the fifth cranial nerve due to the age-related decrease in VZV-specific cell-mediated immunity. ${ }^{12,13}$ During the infection, occlusive iris vasculitis develops and the virus antigen has been detected in the stroma and vascular endothelial cells of the iris. ${ }^{14}$ Surprisingly, the widespread use of varicella vaccine today may not have lessened the incidence of zoster infection and indeed has been reported to trigger it. ${ }^{15,16}$

\section{Cytomegalovirus}

CMV infection is often subclinical or may cause a mild flulike illness that goes unnoticed. It is unclear how the virus enters the eye but inclusion bodies have been identified in the iris, ciliary body, cornea endothelium, and the trabecular meshwork in the immunocompromised. ${ }^{17}$ The virus is known to remain latent in monocytes until reactivated. CMV can cause an acute, recurrent, hypertensive, or chronic anterior uveitis. It presents at a younger age in the acute form (third to fifth decade) than in the chronic (fifth to seventh decade) form; but in both the entities, there is a male predominance. ${ }^{18}$

\section{Variations in geographic distribution}

While HSV and VZV infections occur worldwide without a racial predilection, CMV uveitis has predominantly been reported among the Chinese and Japanese. ${ }^{19-21}$ Chee et al from Singapore reported on eyes with hypertensive anterior uveitis and found that the majority was positive for CMV (88.5\%) or HSV but not for VZV on aqueous polymerase chain reaction (PCR) analysis. ${ }^{21}$ In contrast, Babu et al from South India found that of PCR-proven viral anterior uveitis, two-thirds were positive for VZV, $19.4 \%$ for HSV, and $8.3 \%$ for CMV. ${ }^{10}$ On the other hand, Miserocchi et al reported 241 cases of viral ocular infection in an Italian population of which 42 had solely anterior uveitis. HSV (83.3\%) was the most common cause, followed by VZV (11.9\%) and CMV. ${ }^{22}$

\section{Clinical features}

\section{Herpes simplex virus}

This typically presents acutely with an injected eye and raised intraocular pressure (IOP) in $38 \%-90 \%$ of eyes. ${ }^{22,23}$ Careful observation may reveal the presence of corneal scars in $33 \%$ of cases and a reduced corneal sensation. ${ }^{24}$ Keratic precipitates (KPs) may be granulomatous or nongranulomatous, and the anterior chamber activity is generally moderate with flare and cells. There may be dilated iris blood vessels and segmental iridoplegia with flattening of the pupil. Posterior synechiae may develop in $38 \%$ of cases. ${ }^{24}$ There may be corectopia or sectoral iris transillumination defects from previous episodes causing iris epithelial or stromal defects in up to $50 \%$ of cases, which in severe cases may induce glare. ${ }^{24}$ Diffuse iris atrophy is uncommon ( $10 \%$ of eyes). ${ }^{24}$ Vitritis may be seen in $43 \%$ of eyes. ${ }^{24}$ Rarely, HSV has been reported to cause Posner-Schlossman syndrome (PSS), Fuchs uveitis syndrome, or acute iris depigmentation and pigmentary glaucoma. ${ }^{25-27}$ The inflammation becomes chronic with persistently raised IOP unless specific antiviral therapy is instituted.

Although both HSV-1 and HSV-2 can cause ocular infections such as acute retinal necrosis, HSV-1 is more commonly detected in association with keratouveitis and anterior uveitis than HSV-2. ${ }^{28}$ As most authors do not subtype the HSV, there is a lack of data regarding the differences in clinical presentation, if any.

\section{Herpes VZV}

Acute hypertensive anterior uveitis with granulomatous or nongranulomatous KPs may present 2 weeks following the eruption of vesicles in the distribution of the ophthalmic branch of the trigeminal nerve. Alternatively, it may present without dermopathy (herpes zoster sine herpete). Moderate anterior chamber cellular activity and flare develop, with iridoplegia and posterior synechiae in $40 \%$ of cases ${ }^{24}$ Corneal scars may be observed in $25 \%$ of cases. ${ }^{24}$ The KPs, which 
may be small or medium sized, and trabecular meshwork tend to become pigmented even without treatment, and the IOP that is elevated in $40 \%{ }^{22}-75 \%$ of cases may become recalcitrant to therapy. ${ }^{20}$ Patchy or sectoral iris atrophy may develop in up to $88 \%$, but diffuse iris atrophy has not been reported. The severity of iris atrophy and pupil distortion is closely associated with the aqueous viral load. ${ }^{29}$ Vitritis develops in $83 \%$ of eyes. ${ }^{24}$

\section{Cytomegalovirus}

Acute CMV anterior uveitis

The acute recurrent hypertensive anterior uveitis associated with CMV is also known as PSS. The eye is usually not injected or may be mildly so, secondary to the acute rise in IOP. The mean presenting IOP is $50 \mathrm{mmHg} .{ }^{18}$ A few small- and medium-sized KPs are seen centrally. The anterior chamber cells are few at this stage and may increase from $1+$ to $2+$ over the next few days. Flare is minimal, and posterior synechiae are absent. The iris may manifest patchy or diffuse stromal atrophy, rarely sectoral. ${ }^{21,30}$ With repeated episodes that may be transient and self-limiting, the patient may progressively lose vision from glaucomatous optic neuropathy.

\section{Chronic CMV anterior uveitis}

In chronic anterior uveitis associated with CMV, eye discomfort and blurring are the usual presenting symptoms. There may be mild ocular injection, diffuse fine or stellate KPs scattered uniformly across the endothelium, and moderate anterior chamber activity. Flare is minimal, and posterior synechiae are absent. The iris may show patchy or diffuse stromal atrophy but without heterochromia even in advanced cases. The IOP may be elevated, but the magnitude of pressure is not as high as that in the acute disease. ${ }^{21}$

\section{Features common to acute and chronic CMV anterior uveitis}

In both the acute and chronic CMV anterior uveitis, the KPs may be distributed in a ring pattern to form coin-shaped lesions, which are pathognomonic of CMV. ${ }^{31} \mathrm{KPs}$ may also be noted to be in a linear pattern just above the limbus inferiorly. ${ }^{21}$ Another characteristic finding is nodular endothelial lesions, which are round, white, and centrally positioned and have a translucent surrounding halo. Seen more commonly in the chronic anterior uveitis, they are associated with CMV infection and may represent infected swollen endothelial cells. They become pigmented over time. ${ }^{18}$ Small patches of endotheliitis may also occur with uveitis, and immune ring formation has also been reported. ${ }^{32}$
Miyanaga et al showed that an inverse correlation between the aqueous viral load with the endothelial cell count exists. Indeed, a reduced endothelial cell count may strengthen the suspicion of CMV in the absence of keratitis. ${ }^{33}$

A recent publication described the presence of posterior segment manifestations other than retinitis associated with these CMV anterior segment infections. They include a delay in arm-retina time, epiretinal membrane, macular edema, disk swelling, and periphlebitis. ${ }^{34}$

\section{Diagnostic approach}

A viral infection of the anterior segment is suspected in the presence of the following features: raised IOP at presentation, iris atrophy, corneal scars, and fresh pigmented KPs. Table 1 summarizes the differences among the three herpes viruses discussed in this article. VZV and CMV tend to be unilateral, while HSV may be bilateral in $18 \%$ of eyes. ${ }^{21,35}$ The clinical course varies among the three viruses, being recurrent in HSV, acute or chronic in CMV, and chronic in VZV anterior uveitis.

When present, skin lesions in the neural distribution of the ophthalmic branch of the trigeminal nerve help differentiate VZV from HSV-1 anterior uveitis, which may be preceded by crops of vesicles on the eyelids.

Corneal involvement may be seen in all three viral infections but differ in type. Both HSV and VZV are associated with decreased corneal sensitivity and neurotrophic ulcer. HSV ( $57 \%-61 \%$ of eyes) is associated with dendritic ulcer, disciform keratitis, and interstitial keratitis. ${ }^{35,36} \mathrm{VZV}(58 \%$ of eyes) may cause dendritiform ulcer, nummular keratitis, and limbal keratitis. Immune ring keratitis has been reported in CMV infection. ${ }^{32,35,36}$

The KPs in acute and chronic CMV are quite characteristic in appearance and distribution, especially if accompanied by coin-like lesions or nodular endothelial lesions. However, the fine or stellate diffusely distributed KPs in the chronic CMV anterior uveitis should be differentiated from Fuchs uveitis syndrome caused by other viruses such as rubella, in which the KPs look similar but do not become pigmented and persist despite treatment.

Iris atrophy occurs in $41 \%-51 \%$ of eyes in HSV, $25 \%-88 \%$ of eyes in VZV, $43 \%$ of eyes in acute CMV anterior uveitis, and $60 \%$ of eyes in chronic CMV anterior uveitis. ${ }^{18,31,35,36}$ Sector iris atrophy may be caused by HSV, VZV, or CMV but spiral atrophy typically associated with VZV. Diffuse atrophy is more commonly associated with CMV or rubella but can also be caused by HSV. HSV and VZV may cause atrophy of the stromal or pigment epithelial layer, whereas CMV tends to mainly affect the stromal layer. 
Table I The comparison of the epidemiology, clinical features, complications, and clinical course among the three herpes viruses

\begin{tabular}{|c|c|c|c|c|}
\hline & HSV & VZV & CMV acute & CMV chronic \\
\hline Age & $30-50$ years & $50-70$ years & $20-50$ years & 40-70 years \\
\hline Sex & Equal & Equal & Males (65\%) & Males $(80 \%)$ \\
\hline Race & All & All & Predominantly Asian & Predominantly Asian \\
\hline Laterality & Bilateral in $18 \%$ of eyes & Unilateral & Unilateral & Predominantly unilateral \\
\hline Skin involvement & \pm crops of vesicles & \pm va dermatome blisters & None & None \\
\hline \multirow[t]{2}{*}{ Cornea } & Scars $12 \%-33 \%$ & Scars $2.5 \%-9 \%$ & \pm nodular endothelial & \pm nodular endothelial \\
\hline & Corneal involvement 57\%-61\% & Corneal involvement $58 \%$ & lesions $26 \%$ & lesions $60 \%$, immune ring \\
\hline Corneal sensation & Reduced & Reduced & Normal & Normal \\
\hline $\mathrm{KP}$ & $\begin{array}{l}\text { Granulomatous or } \\
\text { nongranulomatous }\end{array}$ & $\begin{array}{l}\text { Granulomatous or } \\
\text { nongranulomatous }\end{array}$ & Granulomatous & $\begin{array}{l}\text { Fine, stellate, diffuse } \pm \\
\text { pigmented }\end{array}$ \\
\hline AC cells & Moderate & Moderate & Few & Moderate \\
\hline AC flare & Moderate & Moderate & Minimal & Minimal \\
\hline Pupil shape & May be irregular & May be irregular & Normal & Normal \\
\hline Posterior synechiae & May be present $25 \%-38 \%$ & May be present $0 \%-40 \%$ & Absent & Absent \\
\hline Iris atrophy & Sector or spiral $25 \%-46 \%$ & Sector, circular 25\%-88\% & $\begin{array}{l}\text { Patchy or diffuse, } \\
\text { rarely sector } 43 \%\end{array}$ & Diffuse or patchy $60 \%$ \\
\hline IOP & Elevated $38 \%-90 \%$ & Elevated $40 \%-75 \%$ & Elevated $100 \%$ & Elevated $69 \%$ \\
\hline Vitritis & $43 \%$ & $83 \%$ & $0 \%$ & $9 \%$ \\
\hline Glaucoma & Present in $18 \%-54 \%$ & Present in $30 \%-40 \%$ & $23 \%$ & $36 \%$ \\
\hline Cataract & Present in $28 \%-35 \%$ & Present in $27 \%-30 \%$ & $23 \%$ & $75 \%$ \\
\hline Recurrence & $\ln 15 \%-65 \%$ & $\ln |3 \%-5| \%$ & $100 \%$ & NA \\
\hline
\end{tabular}

Abbreviations: HSV, herpes simplex virus; VZV, varicella-zoster virus; CMV, cytomegalovirus; va, cranial nerve VI; KP, keratic precipitate; AC, anterior chamber; IOP, intraocular pressure.

\section{Laboratory investigations}

Although viral serology may be helpful in excluding a viral etiology when negative, the presence of immunoglobulin $\mathrm{G}$ (IgG) is not helpful in confirming the diagnosis as most adults would have had prior exposure to these viruses. A positive IgM indicates concurrent active systemic infection but does not prove ocular infection. Viral cultures are too slow and lack sensitivity.

Today, PCR analysis of aqueous sampled at the slit lamp or with the patient supine under aseptic conditions for viral DNA is the most commonly used technique to confirm the diagnosis during the acute phase. Goldmann-Witmer coefficient, which determines local intraocular antibody production against the virus, generally taken to be positive when the value exceeds 3 , is another useful test that may take up to 2 weeks to become positive in the acute phase, but remains positive in chronic uveitis. In the immunocompromised, PCR is more useful than Goldmann-Witmer coefficient. Combining both tests increases the sensitivity. As false negatives may occur, these tests may need to be repeated and should best be done during the spike of IOP (if present), especially when suspecting CMV prior to initiating therapy. ${ }^{21}$ Interestingly, viruses may coexist in an ocular infection. ${ }^{37}$ Thus, the first step of screening for viruses can be done using quantitative PCR, followed by real-time PCR to confirm the finding and to quantify the virus. The purpose is twofold: first, to help to identify the virus that is causing the infection based on the viral load, and second, to determine the appropriate treatment. ${ }^{28}$

\section{Differential diagnoses}

Although PSS has been most frequently associated with $\mathrm{CMV}$, the association with HSV has also been reported. ${ }^{25}$ In some cases of PSS, PCR analysis of aqueous is repeatedly negative and may thus be due to an unknown virus. Fuchs uveitis syndrome is associated with rubella in the West and CMV in East Asia, although the association with HSV has also been reported. ${ }^{26,38}$ Very often, there may not be sufficient clinical features to help one differentiate HSV from VZV or CMV, and aqueous analysis is required to confirm the diagnosis in order to guide therapy. Clinical features are summarized in Table 1.

\section{Therapy}

\section{Herpes simplex virus}

The treatment of HSV keratitis has been well studied, but these studies were not powered to evaluate the role of acyclovir (ACV) in the treatment of anterior uveitis. However, the data suggest that the duration of anterior uveitis may be shortened by the prompt use of therapeutic doses of antiviral therapy and that maintenance therapy may be effective in decreasing disease recurrence. ${ }^{39,40}$ Most cases of HSV anterior uveitis are controlled with topical corticosteroids to reduce the anterior segment inflammation, cycloplegics such 
as cyclopentolate $1 \%$ bid to reduce pain and prevent posterior synechiae, and oral ACV $400 \mathrm{mg}$ five times daily in 4 weeks. In severe or recurrent disease, maintenance therapy of ACV $400 \mathrm{mg}$ bid is effective in preventing relapse. Alternatively, valacyclovir (Val), which is a prodrug with improved bioavailability, may be used at a dose of $500 \mathrm{mg}$ three times a day (tds) for treatment and $500 \mathrm{mg}$ bid for maintenance. Systemic antiviral therapy should be combined with lowdose corticosteroid drops for years, if not for life, to prevent relapse. In eyes with raised IOP, antiglaucoma medications are given topically such as timolol maleate $0.5 \%$. Eyes with severe elevation of IOP require oral carbonic anhydrase inhibitors, and filtration surgery may be indicated in medically uncontrolled glaucoma with optic neuropathy.

When preparing the eye for surgery, such as cataract removal, the eye should be quiescent and prophylactic oral antiviral and topical corticosteroids may be beneficial.

\section{Varicella-zoster virus}

When treating acute VZV infection, ACV $800 \mathrm{mg}$ five times daily for 10 days given within 72 hours of onset of skin lesions reduces incidence and severity of episcleritis, dendritiform keratopathy, stromal keratitis, and anterior uveitis. However, the duration of treatment for chronic VZV anterior uveitis should be for at least 4 weeks or longer, especially if the patient is immunocompromised. ${ }^{29}$ The maintenance dose of ACV $400 \mathrm{mg}$ tds may be beneficial to prevent relapse. Alternatively, Val $1 \mathrm{~g}$ tds or famciclovir $500 \mathrm{mg}$ three times daily may be used. Topical steroids given to control the inflammation must be tapered very slowly to avoid rebound inflammation. ${ }^{40}$

\section{Cytomegalovirus}

CMV infection should be treated with ganciclovir or valganciclovir. Various modes of antiviral therapy have been tried, and they include oral valganciclovir $900 \mathrm{mg}$ bid for 6 weeks followed by $450 \mathrm{mg}$ bid for another 6 weeks or more, intravitreal $2 \mathrm{mg} / 0.1 \mathrm{~mL}$ weekly for 3 months, topical ganciclovir gel $0.15 \%$ five times daily for 3 months, and ganciclovir implant and intravitreal ganciclovir $(2 \mathrm{mg} / 0.05 \mathrm{~mL})$ followed by oral valganciclovir. ${ }^{41,42}$

Systemic therapy and implant resulted in a good response but were associated with a high relapse rate. Intravitreal injections had lower response and high relapse rate. Combining intravitreal injections with systemic antiviral therapy appeared to give good outcomes over a 15-month follow-up. Recently, Sobolewska et al found that $64 \%$ can stop therapy without relapse after a mean of 14 months of continuous oral valganciclovir, but this duration may vary with the individual. ${ }^{43}$

In the clinical setting, the treatment of each case varies and is customized to the severity of the disease. It is important to highlight that antiviral therapy reduces viral replication but does not eradicate it. Furthermore, valganciclovir can potentially cause bone marrow and renal toxicity. When prescribing these antivirals, monitoring of full blood count and renal function are important as the dose of medication may require adjustment. In addition to these potential side effects, cost is another issue that requires consideration, especially when these medications may be given for a prolonged period. Hence, in mild disease, treatment is administered topically, reserving the systemic therapy to more severe cases. As CMV causes visual loss by inducing glaucomatous optic neuropathy, cataract, or endothelial cell loss, these risk factors are taken into consideration when deciding upon therapy. The approach to treatment for CMV anterior uveitis is summarized in Figure 1.

In the acute recurrent hypertensive uveitis associated with CMV where the viral load is low and recurrences are infrequent, treatment may take the form of ganciclovir gel $0.15 \%$ five times daily for treatment $(0.15 \%$ Virgan gel; Laboratoires Théa, Clermont-Ferrand, France). ${ }^{41}$ Topical corticosteroids should be given if there is significant inflammation, for example, prednisolone acetate $1 \% \mathrm{bd}$. This may then be tapered and replaced by topical nonsteroidal anti-inflammatory drugs (NSAIDs) such as ketorolac tromethamine $0.4 \%$ qid. When treating the IOP that may attain levels far higher than that encountered in HSV and VZV, prostaglandin analogs that have been reported to trigger CMV anterior uveitis should be the last option. ${ }^{20,42}$

In eyes with chronic CMV anterior uveitis with a moderately high viral aqueous load of $10^{5}$ or more copies of viral $\mathrm{DNA} / \mathrm{mL}$ of aqueous, treatment may be initiated with topical ganciclovir with anti-inflammatory \pm antiglaucoma treatment outlined in the "Acute CMV anterior uveitis" section. If the inflammation responds poorly, especially if the IOP remains persistently elevated, a switch of the antiviral therapy from topical to systemic should be considered. These severe cases that are recalcitrant to topical therapy will often respond to oral valganciclovir $900 \mathrm{mg}$ bid initially for 4-6 weeks and then reduced to the maintenance dose of $450 \mathrm{mg}$ bid until the repeat aqueous PCR converts to negative. ${ }^{41}$

There is a tendency for $80 \%$ of acute anterior uveitis and $86 \%$ of chronic anterior uveitis cases to relapse after successful treatment for 3 months (91\% of acute anterior uveitis cases and $88 \%$ of chronic anterior uveitis cases respond 


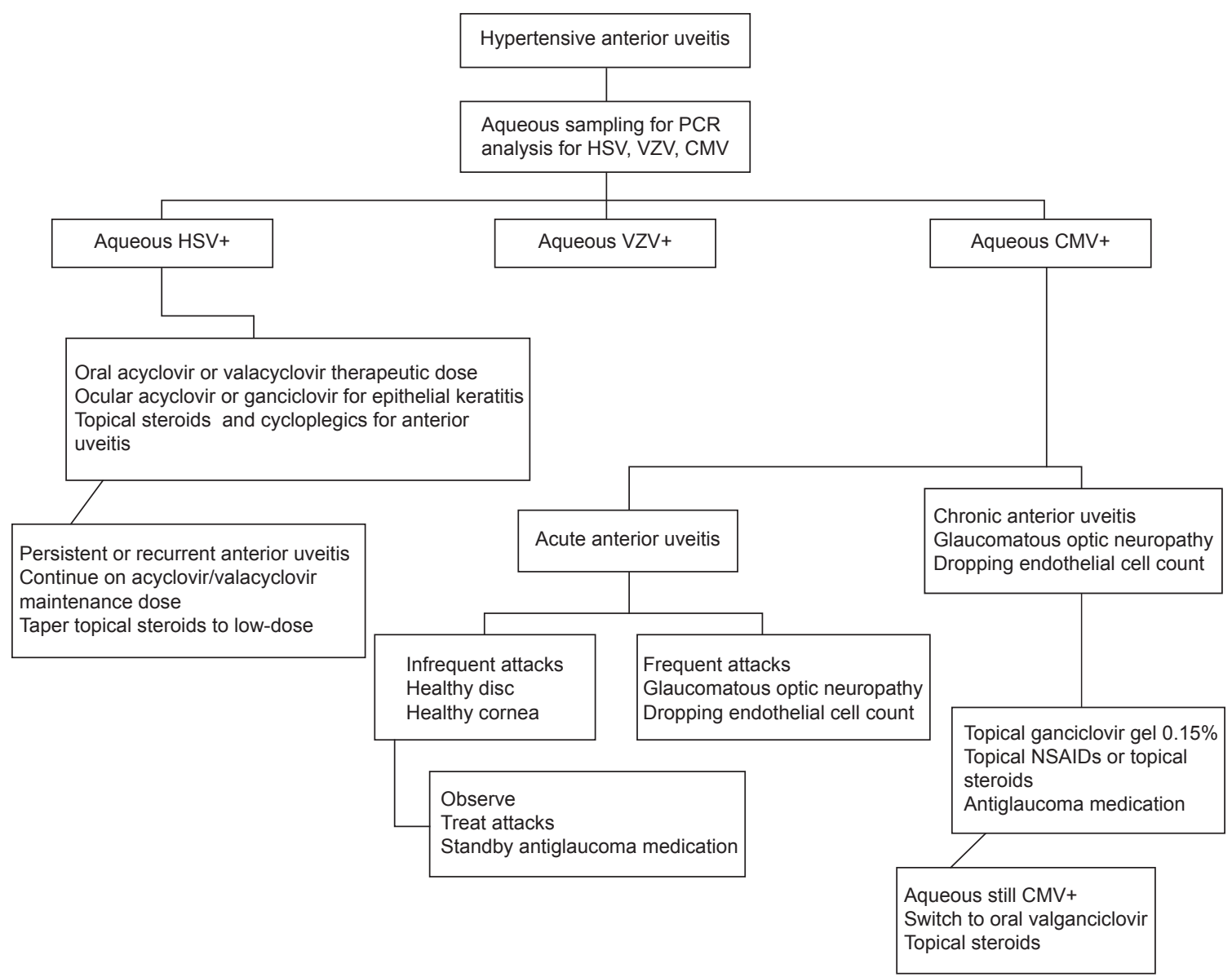

Figure I Treatment approach to herpetic anterior uveitis.

Abbreviations: PCR, polymerase chain reaction; HSV, herpes simplex virus; VZV, varicella-zoster virus; CMV, cytomegalovirus; NSAIDs, nonsteroidal anti-inflammatory drugs.

to therapy). ${ }^{41}$ Hence, some patients are unable to come off therapy and may require topical or maintenance dose of oral antiviral therapy combined with topical NSAIDs indefinitely with antiglaucoma medications. Figure 2 summarizes the suggested treatment approach.

\section{Prognosis}

Generally, the prognosis of viral anterior uveitis is good if diagnosed correctly and treated with specific antiviral therapy and topical steroids or NSAIDs. Cataract develops in $28 \%-35 \%$ of HSV , $27 \%-30 \%$ of VZV, $23 \%$ of acute, and $75 \%$ of chronic CMV anterior uveitis eyes. ${ }^{18,22,24}$ Glaucoma occurs in $18 \%-54 \%$ of eyes with HSV, $30 \%-40 \%$ of eyes with VZV, $23 \%$ of eyes with acute CMV anterior uveitis, and $36 \%$ of eyes with chronic CMV anterior uveitis. ${ }^{18,22,24}$ Despite modern antiglaucoma medication, 60\% of CMV anterior uveitis may still require glaucoma surgery to prevent visual loss. ${ }^{43,44}$ An awareness of the presentation of viral anterior uveitis and how to investigate and treat is of paramount importance since missing the diagnosis and treating only with steroids may result in intractable glaucoma, cataract, and loss of vision.

\section{Summary of herpes associated anterior uveitis}

$\mathrm{HSV}, \mathrm{VZV}$, and CMV may present with hypertensive anterior uveitis. Hypertensive anterior uveitis usually presents acutely except CMV chronic anterior uveitis. HSV presents in the fourth decade, VZV in the sixth decade, and CMV from third up to the ninth decade of life. CMV more commonly tends to affect males and Asians. Most herpetic ocular involvement is unilateral except for HSV, which may be bilateral. Reduced corneal sensation, scars, and neurotrophic ulcers may be associated with HSV and VZV but not with CMV. KPs may be granulomatous or nongranulomatous in HSV and VZV diseases, but are granulomatous in acute CMV and fine, stellate, and evenly distributed in chronic CMV anterior uveitis.

Anterior chamber activity may vary from mild to moderate. Posterior synechiae and sector iris atrophy may develop 


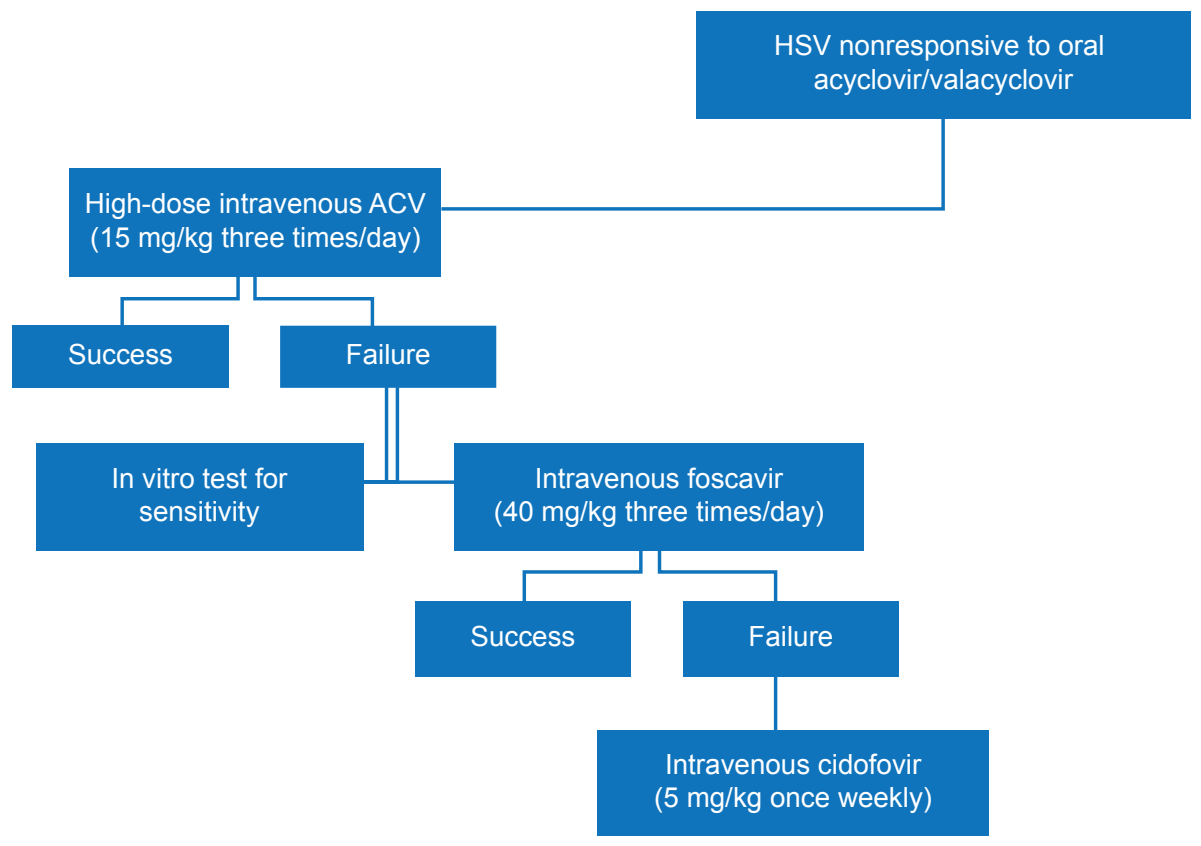

Figure 2 Treatment approach if HSV is nonresponsive to oral (valacyclovir) ACV treatment.

Abbreviations: HSV, herpes simplex virus; ACV, acyclovir.

in HSV and VZV anterior uveitis but CMV anterior uveitis is associated with patchy or diffuse stromal iris atrophy. Vitritis is common in VZV, less frequent in HSV, and rare in CMV anterior uveitis. Cataract and glaucoma are complications common to all herpes viruses.

Diagnosis may be confirmed by aqueous PCR. Treatment is with specific antiviral therapy combined with topical steroids and/or NSAIDs. Maintenance therapy may be required to prevent recurrence.

\section{Herpes virus-associated posterior uveitis \\ Epidemiology}

Acute retinal necrosis (ARN) syndrome, first reported by Urayama et al is a serious progressive ocular condition characterized by retinal necrosis, retinal vasculitis, and intraocular inflammation. ${ }^{45}$ The causative agents are VZV, HSV-1, HSV-2, and rarely, CMV or Epstein-Barr virus. ${ }^{46,47}$ Data from a British registry reported an incidence of $0.5-0.63$ patients/year of ARN, a number that remained fairly stable over the last decade and has been recently confirmed in a German survey. ${ }^{48,49}$ There is a consistent finding that relates the subtype of virus with patient's age. VZV is more likely to be found in middle-aged and older patients, whereas HSV-1 and HSV-2 are the predominant cause in young adults and children. ${ }^{50,51}$ This may have direct therapeutic and prognostic consequences. VZV-induced infections have an overall poorer prognosis that may need a higher antiviral treatment. ${ }^{52,53}$ The reason for the poorer outcome of VZVARN probably relates to specific viral features and/or agerelated changes. Although the detailed pathophysiology of ARN remains unclear, it is believed to be a local reactivation of latent persisting viruses. Clearly, the immune response plays an important role in ARN, underlined by the finding of peripheral VZV-primed T lymphocytes that are temporarily suppressed in ARN patients. ${ }^{54}$

Even when CMV-ARN is uncommon in HIV-negative individuals, it needs attention. Even a rather limited immune dysfunction related to advanced age $(n=4)$, diabetes mellitus $(n=4)$ and noncytotoxic immunotherapy $(n=3)$ was identified as the underlying cause. ${ }^{47}$

\section{Clinical features}

Typical clinical features include a rapid onset of pan-uveitis, dominated initially by vitritis, vasculitis, and retinitis in the peripheral retina. ${ }^{55}$ Rapid spread, both circumferently and centrally, occurs within hours and few days. Typically, the retinitis presents as either confluent or multifocal patches of retinitis. ${ }^{55}$ The destructive nature of the disorder is related to the rapid extension of vasculitis involving both retinal as well as choroidal vessels and occlusive periarteritis. Most important, approximately one-third of patients may suffer from (milder) involvement of the second eye, probably by spreading over the optic nerve. This occurs typically within 6 weeks, but may present even decades following the initial infection. ${ }^{55,56}$ The risk of bilateral infection may be 
decreased with prompt antiviral therapy. ${ }^{57}$ An anterograde (forward) expansion of infection was resolved yielding new mutations, which may be important for neuroinvasiveness. ${ }^{58}$ Possibly, intraocular persistent viruses have acquired additional mutations, which allowed them to migrate into the contralateral optic nerve and the eye. Progression of retinitis can be commonly controlled within 2-4 weeks, when immediate treatment is instilled. When the acute course has subsided, retinal thinning and atrophy remains with often sharply demarked areas predisposing for retinal breaks. ${ }^{59,60}$ Additional inflamed vitreous organization results in proliferative vitreoretinopathy. In up to $70 \%$ of the primarily affected eyes, rhegmatogenous retinal detachment (RD) occurs. ${ }^{60-63}$ Further complications of ARN may include chronic vitritis, macular edema, optic atrophy, epiretinal membrane formation, and viral relapse with cessation of antiviral medication. ${ }^{63}$

\section{Diagnostic approach}

The commonly used diagnostic criteria and definition so far have been purely based on clinical findings. ${ }^{64}$ Recently, a modification has been suggested by the Japanese ARN Study Group that seems overdue, since it not only includes a graduation of intraocular findings but also emphasizes determination of the exact viral etiology. ${ }^{65}$

\section{Laboratory investigations}

For diagnostic purpose, a small sample volume $(50-100 \mu \mathrm{L})$ of aqueous humor is sufficient to detect the presence of VZV, HSV, or CMV-DNA. ${ }^{59,66-68}$ Sensitivity and specificity of PCR to detect VZV, HSV, or CMV in these patients is $95 \%, 94 \%$, and $97 \%$, respectively, and is higher in immunocompromised patients. ${ }^{69-71}$ The use of quantitative PCR may even allow to monitor the viral load, providing additional helpful information leading to potential therapeutic consequences. ${ }^{72,73}$ The differentiation between HSV and VZV as most frequent etiologies of ARN may have therapeutic and prognostic consequences. A large study based on 81 eyes confirmed that VZV infection results in poorer prognosis with more severe damage and sequela when compared to HSV. RD was 2.5-fold more common in VZV-affected eyes and a significantly greater degree of visual loss $(P=0.016)$ was reported (62\%) as compared to HSV-ARN (24\%). Therefore, viral identification may serve as a key to predict outcome in these patients. ${ }^{52}$

Atypical presentations of other etiologies need to be excluded and treated completely different. This includes syphilitic retinitis, toxoplasmic retinochoroiditis, intraocular lymphoma, sarcoidosis, tuberculosis, toxocariasis, Behçet's disease, and other retinal vasculitides.

\section{Therapy}

\section{Systemic antiviral treatment}

As soon as typical clinical findings are present, antiviral treatment needs to be initiated.

Since the causative role of VZV, HSV-1, HSV-2, or CMV can be distinguished, a clear target for therapy is established. As it might be expected, no randomized controlled trials are available; however, a clear treatment strategy is required to cope with this often fatal disorder. The standard of care in ARN remains intravenous (IV) administration of ACV since its gastrointestinal absorption varies significantly. ${ }^{74}$ The half-life of ACV lasts $\sim 3$ hours only. Therefore, it is initially necessary to apply ACV three times daily at a dosage between $10 \mathrm{mg} / \mathrm{kg}$ and $15 \mathrm{mg} / \mathrm{kg} .{ }^{74}$ In patients who are likely to be infected with VZV, the higher concentration of ACV should be chosen. IV treatment should be continued for at least 7 days, before medication can be switched to oral administration.

Several small pilot studies $(n=10)$ suggested the use of oral agents such as Val-ACV (three times daily at a dosage of 1,000 mg) and famciclovir (three times daily $500 \mathrm{mg}$ ) instead of initial IV administration. ${ }^{75,76}$

Since ACV (commonly given at a daily dosage of three to five times $800 \mathrm{mg}$ ) is eliminated mainly via the kidneys, patients with impaired renal function have a prolonged halflife in the circulation and higher serum concentrations. ${ }^{77}$ This may relate to kidney and central nervous system toxicity. ${ }^{78}$ Because VZV is more likely to occur in older patients with already higher risk of renal problems, this needs to be taken into account.

\section{Intravitreal antiviral treatment}

Limited data are available on the combined use of systemic ACV plus foscarnet. Foscarnet is even more nephrotoxic than ACV; therefore, combined systemic treatment bears additional risks. Subsequently, the intravitreal use of foscarnet has been favored allowing higher drug bioavailability and circumventing systemic exposure. It improved the prognosis regarding visual function and reduced the risk of RD. ${ }^{79}$ Wong et al reported that eyes treated with additional intravitreal foscarnet $(n=56)$ had a $40 \%$ lower rate of $R D$ in VZV-ARN (53.6\% vs 75.0\%). ${ }^{79}$ In another 2-year follow-up study, patients receiving a combination of systemic and intravitreal antiviral therapy had a two-line or greater visual acuity improvement and again a reduction in RD. ${ }^{80}$ 
Similar observations were reported by Meghpara et al. Three of the four eyes with extended ARN (25\%-50\% retina involvement) receiving intravitreal foscarnet had an improvement in visual acuity of two or more Snellen lines. ${ }^{63}$ It might be concluded that the higher concentration of intravitreal medication results in more effective control of viral replication, with subsequent prevention of retina necrosis and destructive sequela. ${ }^{79}$ In practical terms, the typical dose of $2.4 \mathrm{mg} / 0.1 \mathrm{~mL}$ intravitreal foscarnet can be administered without dilution from the commercially available IV solution. We and others administer intravitreal foscarnet in highly suspected patients directly at the time when diagnostic aqueous humor sampling is performed.

Intravitreal injections of ganciclovir have also been used for the treatment of active CMV-ARN given two or three times weekly $(2 \mathrm{mg} / 0.1 \mathrm{~mL}){ }^{63,81}$

Not all reports are in line with improved outcomes using newer antiviral strategies, eg, Val-ACV, famciclovir, or intravitreal applications. Tibbetts et al reported similar clinical results comparing patients treated with ACV-only $(n=36)$ and those with newer approaches $(n=22) .{ }^{82}$ In both the groups, functional outcome (20/200 or worse) was seen in $24 \%$ per person-year $(P=0.91)$. The risk of $\mathrm{RD}$ was approximately $50 \%$ in each group $(P=0.59)$. However, given the unstratified design of the study and comparison of small subgroups, these conclusions are limited..$^{2}$

\section{Prevention of second eye involvement}

Preventing the risk of virus spreading to the fellow eye is an essential treatment goal and strongly advocates prolonged oral treatment. So far, no controlled studies on the important question of how long treatment needs to be kept are available. A minimum period of 6 weeks seems rational, since most occurrences in the second eye develop within this time. A recent survey among German uveitis centers report that oral antiviral treatment was continued for 6 months in $27 \%$ of respondents, followed by 3 months (24\%), and was even extended over 12 months in $18 \%$ of respondents. ${ }^{49}$

\section{Resistance to ACV}

The widespread use of ACV and the increasing number of immunocompromised patients led to an increase in ACVresistant HSV. Still, resistance to ACV is relatively rare. So far, only case reports have been suggestive that HSV-resistant strains may become a problem in ARN..$^{83,84}$ Resistance is more a concern in immunocompromised hosts with a frequency between $2.5 \%$ and $14 \% .{ }^{85}$ If ACV-resistant HSV and VZV strains are suspected, foscarnet should be used since it does not require activation by thymidine kinase. Ganciclovir-resistant CMV strains are also sensitive for foscarnet; however, the rate of foscarnet resistance in CMV is increasing. ${ }^{84,86,87}$

\section{Anti-inflammatory treatment}

The role of steroids in ARN remains controversial. There are many documented cases when systemic or intravitreal injected steroids provoked the onset of ARN. ${ }^{88,89}$ The fulminant inflammatory nature of the disease and highly upregulated proinflammatory cytokines (eg, IL-6 and interferon gamma), however, suggest that suppression of intraocular inflammation is important. ${ }^{90}$ Systemic corticosteroids $(0.5-1 \mathrm{mg} / \mathrm{kg} / \mathrm{day})$ have been suggested to alter the progression. ${ }^{90}$ There was however a tendency of higher RD rate in patients receiving steroids. The authors suggested that this correlation was due to more severely affected eyes with a higher likelihood for this complication. ${ }^{79}$

\section{Anticoagulation}

ARN often leads to occlusive retinal arteritis that may result in optic nerve head damage, raising the question for antithrombotic treatment. A low-dose approach using aspirin (100 mg/day) is often implemented, but its value and benefit remains controversial. Again, for the more severe course of VZV infection, a higher dose (300 mg/day) has been suggested. ${ }^{79}$

\section{Laser photocoagulation}

Since there is a remarkable high rate of $\mathrm{RD}$, in particular, in VZV-ARN, we and others place a multiple row of laser spots posterior to the affected necrotic area whenever possible. ${ }^{60,91}$ However, the role of photocoagulation in patients with ARN remains controversial, and an earlier study reported that there was no effective barrier and no prevention for progression. ${ }^{92}$ It was even reported that, as in proliferative diabetic retinopathy, the vitreous-retina adhesion can be destabilized leading to subsequent retinal breaks. ${ }^{93}$

\section{Vitreous surgery}

The role for early, elective vitrectomy remains under debate. ${ }^{94-96}$ Most studies are biased because vitrectomy is more likely performed in severely affected eyes. Several authors conclude that prophylactic vitrectomy did not improve the final outcome in ARN, irrespective of its severity. ${ }^{62,94,96}$ However, we as others have seen patients who profit from early vitreous removal. Major arguments for this invasive management include: 
1. Vitreous material can be used for diagnostic purpose.

2. Removal of inflamed vitreous debris may reduce inflammatory components.

3. Secondary complications (RD) are frequent due to vitreous traction and might be early on prevented.

4. Follow-up in these patients might be improved due to better visualization.

When RD occurs in ARN, there are often both rhegmatogenous and tractional components. Subsequently, both factors need to be addressed. Pars plana vitrectomy, lensectomy, air-fluid exchange, endolaser, and long-acting gas or silicone oil tamponade have shown success in RD repair and recovery of vision. ${ }^{94}$ Since removal of silicone oil is often followed by redetachment, often a permanent tamponade is advocated. Addition of a scleral buckle does not seem to affect visual and anatomical outcomes nor does the use of silicone oil versus gas tamponade. ${ }^{62,95}$ In most patients, despite anatomic success, final visual function remained limited - particularly when the infection has involved the optic nerve and/or macula. ${ }^{94}$

\section{Prognosis}

ARN remains a serious disorder that needs prompt attention and management. Risk factors that determine the visual prognosis in ARN include delay of correct diagnosis, VZV as underlying infection, and high viral copy number in ocular fluid. Despite an overall guarded prognosis, prompt systemic and intravitreal antiviral treatment may result in improved visual outcomes and protection of the second eye.

\section{Conclusion}

Viruses are an important etiology of acute and chronic intraocular inflammation. Ophthalmologists should be aware of the key clinical features and appropriate investigations that are needed for their diagnosis. Prompt identification of the infection requires analysis of intraocular specimen that can limit further unnecessary diagnostic workup and prevent treatment with potentially harmful immunomodulatory agents. Considering the biology of different viruses, their expansion, and persistence in ocular tissues, the treatment needs to be prompt, specific, and long-term continued. Given the high prevalence of herpes viruses and the risk of reactivation in the elderly, this may favor preventive measures. The impact of vaccines that are approved, eg, for VZV in immunocompetent subjects, remains still unclear.

\section{Disclosure}

The authors report no conflicts of interest in this work.

\section{References}

1. Kinchington PR, Leger AJ, Guedon JM, Hendricks RL. Herpes simplex virus and varicella zoster virus, the house guests who never leave. Herpesviridae. 2012;3(1):5.

2. Crough $T$, Khanna R. Immunobiology of human cytomegalovirus: from bench to bedside. Clin Microbiol Rev. 2009;22(1):76-98.

3. Sancho-Shimizu V, Zhang SY, Abel L, et al. Genetic susceptibility to herpes simplex virus 1 encephalitis in mice and humans. Curr Opin Allergy Clin Immunol. 2007;7(6):495-505.

4. Quentin CD, Reiber H. Fuchs heterochromic cyclitis: rubella virus antibodies and genome in aqueous humor. Am J Ophthalmol. 2004; 138:46-54.

5. de Groot-Mijnes JD, de Visser L, Rothova A, Schuller M, van Loon AM, Weersink AJ. Rubella virus is associated with Fuchs heterochromic iridocyclitis. Am J Ophthalmol. 2006;141(1):212-214.

6. Ruokonen PC, Metzner S, Ucer A, Torun N, Hofmann J, Pleyer U. Intraocular antibody synthesis against rubella virus and other microorganisms in Fuchs' heterochromic cyclitis. Graefes Arch Clin Exp Ophthalmol. 2010;248(4):565-571.

7. Takahashi H, Sugita S, Shimizu N, Mochizuki M. A high viral load of Epstein-Barr virus DNA in ocular fluids in an HLA-B27-negative acute anterior uveitis patient with psoriasis. Jpn J Ophthalmol. 2008; 52(2):136-138

8. de Groot-Mijnes JD, de Visser L, Zuurveen S, et al. Identification of new pathogens in the intraocular fluid of patients with uveitis. $\mathrm{Am} \mathrm{J}$ Ophthalmol. 2010;150(5):628-636.

9. Mahendradas P, Shetty R, Malathi J, Madhavan HN. Chikungunya virus iridocyclitis in Fuchs' heterochromic iridocyclitis. Indian J Ophthalmol. 2010;58(6):545-547.

10. Babu K, Kini R, Philips M, Subbakrishna DK. Clinical profile of isolated viral anterior uveitis in a South Indian patient population. Ocul Immunol Inflamm. 2014;22(5):356-359.

11. Young RC, Hodge DO, Liesegang TJ, Baratz KH. Incidence, recurrence, and outcomes of herpes simplex virus eye disease in Olmsted County, Minnesota, 1976-2007: the effect of oral antiviral prophylaxis. Arch Ophthalmol. 2010;128:1178-1183.

12. Wareham DW, Breuer J. Herpes zoster. BMJ. 2007;334(7605): 1211-1215.

13. Liesegang TJ. Herpes zoster virus infection. Curr Opin Ophthalmol. 2004;15(6):531-536.

14. Nakashizuka H, Yamazaki Y, Tokumaru M, Kimura T. Varicella-zoster viral antigen identified in iridocyclitis patient. Jpn J Ophthalmol. 2002; 46:70-73.

15. Esmaeli-Gutstein B, Winkelman JZ. Uveitis associated with varicella virus vaccine. Am J Ophthalmol. 1999;127(6):733-734.

16. Naseri A, Good WV, Cunningham ET Jr. Herpes zoster virus sclerokeratitis and anterior uveitis in a child following varicella vaccination. Am J Ophthalmol. 2003;135(3):415-417.

17. Daicker B. Cytomegalovirus panuveitis with infection of corneo-trabecular endothelium in AIDS. Ophthalmologica. 1988;197(4):169-175.

18. Chee SP, Jap A. Presumed fuchs heterochromic iridocyclitis and PosnerSchlossman syndrome: comparison of cytomegalovirus-positive and negative eyes. Am J Ophthalmol. 2008;146(6):883-889.

19. Anwar Z, Galor A, Albini TA, Miller D, Perez V, Davis JL. The diagnostic utility of anterior chamber paracentesis with polymerase chain reaction in anterior uveitis. Am J Ophthalmol. 2013;155(5): 781-786.

20. Takase H, Kubono R, Terada Y, et al. Comparison of the ocular characteristics of anterior uveitis caused by herpes simplex virus, varicellazoster virus, and cytomegalovirus. Jpn J Ophthalmol. 2014;58(6): 473-482.

21. Chee SP, Bacsal K, Jap A, Se-Thoe SY, Cheng CL, Tan BH. Clinical features of cytomegalovirus anterior uveitis in immunocompetent patients. Am J Ophthalmol. 2008;145(5):834-840.

22. Miserocchi E, Fogliato G, Bianchi I, Bandello F, Modorati G. Clinical features of ocular herpetic infection in an Italian referral center. Cornea. 2014;33(6):565-570. 
23. Van der Lelij A, Ooijman FM, Kijlstra A, Rothova A. Anterior uveitis with sectoral iris atrophy in the absence of keratitis: a distinct clinical entity among herpetic eye diseases. Ophthalmology. 2000;107(6):1164-1170.

24. Wensing B, Relvas LM, Caspers LE, et al. Comparison of rubella virusand herpes virus-associated anterior uveitis: clinical manifestations and visual prognosis. Ophthalmology. 2011;118(10):1905-1910.

25. Yamamoto S, Pavan-Langston D, Tada R, et al. Possible role of herpes simplex virus in the origin of Posner-Schlossman syndrome. Am J Ophthalmol. 1995;119(6):796-798.

26. Barequet IS, Li Q, Wang Y, O’Brien TP, Hooks JJ, Stark WJ. Herpes simplex virus DNA identification from aqueous fluid in Fuchs heterochromic iridocyclitis. Am J Ophthalmol. 2000;129(5): 672-673.

27. Dastrup BT, Cantor L, Moorthy RS, Vasconcelos-Santos D, Rao N. An unusual manifestation of herpes simplex virus-associated acute iris depigmentation and pigmentary glaucoma. Arch Ophthalmol. 2011;129(2):253-254.

28. Sugita S, Shimizu N, Watanabe K, et al. Use of multiplex PCR and real-time PCR to detect human herpes virus genome in ocular fluids of patients with uveitis. Br J Ophthalmol. 2008;92(7):928-932.

29. Kido S, Sugita S, Horie S, et al. Association of varicella zoster virus load in the aqueous humor with clinical manifestations of anterior uveitis in herpes zoster ophthalmicus and zoster sine herpete. Br J Ophthalmol. 2008;92(4):505-508.

30. Markomichelakis NN, Canakis C, Zafirakis P, Marakis T, Mallias I, Theodossiadis G. Cytomegalovirus as a cause of anterior uveitis with sectoral iris atrophy. Ophthalmology. 2002;109(5):879-882.

31. Hwang YS, Shen CR, Chang SH, et al. The validity of clinical feature profiles for cytomegaloviral anterior segment infection. Graefes Arch Clin Exp Ophthalmol. 2011;249:103-110.

32. Chee SP, Jap A. Immune ring formation associated with cytomegalovirus endotheliitis. Am J Ophthalmol. 2011;152(3):449-453.

33. Miyanaga M, Sugita S, Shimizu N, et al. A significant association of viral loads with corneal endothelial cell damage in cytomegalovirus anterior uveitis. Br J Ophthalmol. 2010;94(3):336-340.

34. Wong MH, Cheung GC, Chee SP. Posterior segment findings of ocular cytomegalovirus infection in immunocompetent patients. Graefes Arch Clin Exp Ophthalmol. 2014;252(11):1811-1816.

35. Miserocchi E, Waheed NK, Dios E, et al. Visual outcome in herpes simplex virus and varicella zoster virus uveitis. A clinical evaluation and comparison. Ophthalmology. 2002;109:1532-1537.

36. Tugal-Tutkun I, Otük-Yasar B, Altinkurt E. Clinical features and prognosis of herpetic anterior uveitis: a retrospective study of 111 cases Int Ophthalmol. 2010;30(5):559-565.

37. Kasetsuwan N, Tangmonkongvoragul C. Concomitant herpes simplex virus and cytomegalovirus endotheliitis in immunocompetent patient. BMJ Case Rep. 2013;9:2013.

38. Cimino L, Aldigeri R, Parmeggiani M, et al. Searching for viral antibodies and genome in intraocular fluids of patients with Fuchs uveitis and non-infectious uveitis. Graefes Arch Clin Exp Ophthalmol. 2013;251(6):1607-1612.

39. The Herpetic Eye Disease Study Group. A controlled trial of oral acyclovir for the prevention of stromal keratitis or iritis in patients with herpes simplex virus epithelial keratitis. The Epithelial Keratitis Trial. Arch Ophthalmol. 1997;115(6):703-712.

40. Cobo LM, Foulks GN, Liesegang T, et al. Oral acyclovir in the treatment of acute herpes zoster ophthalmicus. Ophthalmology. 1986;93:763-770.

41. Chee SP, Jap A. Cytomegalovirus anterior uveitis: outcome of treatment Br J Ophthalmol. 2010;94(12):1648-1652.

42. Hwang YS, Lin KK, Lee JS, et al. Intravitreal loading injection of ganciclovir with or without adjunctive oral valganciclovir for cytomegalovirus anterior uveitis. Graefes Arch Clin Exp Ophthalmol. 2010;248:263-269.

43. Sobolewska B, Deuter C, Doycheva D, Zierhut M. Long-term oral therapy with valganciclovir in patients with Posner-Schlossman syndrome. Graefes Arch Clin Exp Ophthalmol. 2014;252(1):117-124.
44. Accorinti M, Gilardi M, Pirraglia MP, et al. Cytomegalovirus anterior uveitis: long-term follow-up of immunocompetent patients. Graefes Arch Clin Exp Ophthalmol. 2014;252(11):1817-1824.

45. Urayama A, Yamada N, Sasaki T. Unilateral acute uveitis with periarteritis and detachment. Jp J Clin Ophthalmol. 1971;25:607-619.

46. Culbertson WW, Blumenkranz MS, Haines H. The acute retinal necrosis syndrome part 2. Histopathol Etiol Ophthalmol. 1982;89(12): 1317-1325.

47. Schneider EW, Elner SG, van Kuijk FJ, et al. Chronic retinal necrosis: cytomegalovirus necrotizing retinitis associated with panretinal vasculopathy in non-HIV patients. Retina. 2013;33:1791-1799.

48. Cochrane TF, Silvestri G, McDowell C, Foot B, McAvoy CE. Acute retinal necrosis in the United Kingdom: results of a prospective surveillance study. Eye. 2012;26(3):370-377.

49. Winterhalter S, Joussen A, Pleyer U, et al. Acute retinal necrosis - a national survey in Germany. In press 2015.

50. Muthiah MN, Michaelides M, Child CS, Mitchell SM. Acute retinal necrosis: a national population-based study to assess the incidence, methods of diagnosis, treatment strategies and outcomes in the UK Br J Ophthalmol. 2007;91(11):1452-1455.

51. Silva RA, Berrocal AM, Moshfeghi DM, Blumenkranz MS, Sanislo S, Davis JL. Herpes simplex virus type 2 mediated acute retinal necrosis in a pediatric population: case series and review. Graefes Arch Clin Exp Ophthalmol. 2013;251(2):559-566.

52. Wong R, Pavesio CE, Laidlaw DA, Williamson TH, Graham EM, Stanford MR. Acute retinal necrosis: the effects of intravitreal foscarnet and virus type on outcome. Ophthalmology. 2010;117(3): 556-560.

53. Ichikawa T, Sakai J, Yamauchi Y, Minoda H, Usui M. A study of 44 patients with Kirisawa type uveitis. Nihon Ganka Gakkai Zasshi. 1997;101(3):243-247.

54. Kezuka T, Sakai J, Usui N, Streilein JW, Usui M. Evidence for antigenspecific immune deviation in patients with acute retinal necrosis. Arch Ophthalmol. 2001;119(7):1044-1049.

55. Fisher JP, Lewis ML, Blumenkranz M, et al. The acute retinal necrosis syndrome part 1: clinical manifestations. Ophthalmology. 1982;89:1309-1316.

56. Okunuki Y, Usui Y, Kezuka T, Takeuchi M, Goto H. Four cases of bilateral acute retinal necrosis with a long interval after the initial onset. Br J Ophthalmol. 2011;95:1251-1254.

57. Palay DA, Sternberg P Jr, Davis J, et al. Decrease in the risk of bilateral acute retina necrosis by acyclovir therapy. Am J Ophthalmol. 1991; 112:250-255

58. Szpara ML, Parsons L, Enquist LW. Sequence variability in clinical and laboratory isolates of herpes simplex virus 1 reveals new mutations. 50-neuroinvasiveness. J Virol. 2010;84(10):5303-5313.

59. Pleyer U, Winterhalter S. [Diagnostic and therapeutic aspects of herpes virus associated uveitis]. Klin Monbl Augenheilkd. 2010; 227(5):407-412.

60. Lau CH, Missotten T, Salzmann J, Lightman SL. Acute retinal necrosis features, management, and outcomes. Ophthalmology. 2007; 114:756-762.

61. McDonald HR, Lewis H, Kreiger AE, Sidikaro Y, Heckenlively J. Surgical management of retinal detachment associated with the acute retinal necrosis syndrome. Br J Ophthalmol. 1991;75:455-458.

62. Ahmadieh H, Soheilian M, Azarmina M, Dehghan MH, Mashayekhi A. Surgical management of retinal detachment secondary to acute retinal necrosis: clinical features, surgical techniques, and long-term results. Jpn J Ophthalmol. 2003;47:484-491.

63. Meghpara B, Sulkowski G, Kesen MR, Tessler HH, Goldstein DA. Longterm follow-up of acute retina necrosis. Retina. 2010;30:795-800.

64. Holland GN. Standard diagnostic criteria for the acute retinal necrosis syndrome. Executive committee of the American Uveitis Society. Am J Ophthalmol. 1994;117(5):663-667.

65. Takase H, Okada AA, Goto H, et al. Development and validation of new diagnostic criteria for acute retinal necrosis. Jpn J Ophthalmol. 2015;59(1):14-20. 
66. Harper TW, Miller D, Schiffman JC, Davis JL. Polymerase chain reaction analysis of aqueous and vitreous specimens in the diagnosis of posterior segment infectious uveitis. Am J Ophthalmol. 2009; $147: 140 \mathrm{e}-147 \mathrm{e}$.

67. Rothova A, de Boer JH, Ten Dam-van LNH, et al. Usefulness of aqueous humor analysis for the diagnosis of posterior uveitis. Ophthalmology. 2008;115:306-311.

68. Abe T, Tsuchida K, Tamai M. A comparative study of the polymerase chain reaction and local antibody production in acute retinal necrosis syndrome and cytomegalovirus retinitis. Graefes Arch Clin Exp Ophthalmol. 1996;234(7):419-424.

69. Cunningham ET Jr, Short GA, Irvine AR, Duker JS, Margolis TP. Acquired immuno deficiency syndrome - associated herpes simplex virus retinitis. Clinical description and use of a polymerase chain reaction-based assay as a diagnostic tool. Arch Ophthalmol. 1996;114:834-840.

70. Short GA, Margolis TP, Kuppermann BD, et al. A polymerase chain reaction-based assay for diagnosing varicella-zoster virus retinitis in patients with acquired immunodeficiency syndrome. Am JOphthalmol. 1997; 123:157-164.

71. Dabil H, Boley ML, Schmitz TM, Van Gelder RN. Validation of a diagnostic multiplex polymerase chain reaction assay for infectious posterior uveitis. Arch Ophthalmol. 2001;119:1315-1322.

72. Cottet L, Kaiser L, Hirsch HH, Baglivo E. HSV2 acute retinal necrosis: diagnosis and monitoring with quantitative polymerase chain reaction. Int Ophthalmol. 2009;29:199-201.

73. Yin PD, Kurup SK, Fischer SH, et al. Progressive outer retinal necrosis in the era of highly active antiretroviral therapy: successful management with intravitreal injections and monitoring with quantitative PCR. J Clin Virol. 2007;38:254-259.

74. De Clercq E. Selective anti-herpes virus agents. Antivir Chem Chemother. 2013;23(3):93-101.

75. Aizman A, Johnson MW, Elner SG. Treatment of acute retinal necrosis syndrome with oral antiviral medications. Ophthalmology. 2007;114:307-312.

76. Huynh TH, Johnson MW, Comer GM, Fish DN. Vitreous penetration of orally. Administered valacyclovir. Am J Ophthalmol. 2008; 145:682-686.

77. MacDougall C, Guglielmo BJ. Pharmacokinetics of valaciclovir. $J$ Antimicrob Chemother. 2004;53(6):899-901.

78. Lee RM, Llewellyn M, Houston A, Hughes EH. Reversible mental status change and renal dysfunction associated with the use of high-dose oral valaciclovir therapy for acute retinal necrosis. Retin Cases Brief Rep. 2012;6:266-268.

79. Wong RW, Jumper JM, McDonald HR, et al. Emerging concepts in the management of acute retinal necrosis. BJOphthalmology. 2013;97(5):545-552.

80. Yeh S, Suhler EB, Smith JR, et al. Combination systemic and intravitreal antiviral therapy in the management of acute retinal necrosis syndrome. Ophthalmic Surg Lasers Imaging Retina. 2014;45(5):399-407.
81. Luu KK, Scott IU, Chaudhry NA, Verm A, Davis JL. Intravitreal antiviral injections as adjunctive therapy in the management of immunocompetent patients with necrotizing herpetic retinopathy. $\mathrm{Am} \mathrm{J}$ Ophthalmol. 2000;129:811-813.

82. Tibbetts MD, Shah CP, Young LH, Duker JS, Maguire JI, Morley MG. Treatment of acute retinal necrosis. Ophthalmology. 2010;117(4): 818-824.

83. Dokey AT, Haug SJ, McDonald HR, et al. Acute retinal necrosis secondary to multidrug-resistant herpes simplex virus 2 in an immunocompetent adolescent. Retin Cases Brief Rep. 2014;8:260-264.

84. Piret J, Boivin G. Resistance of herpes simplex viruses to nucleoside analogues: mechanisms, prevalence, and management. Antimicrob Agents Chemother. 2011;55(2):459-472.

85. Frobert E, Burrel S, Ducastelle-Lepretre S, et al. Resistance of herpes simplex viruses to acyclovir: an update from a ten-year survey in France. Antiviral Res. 2014;111:36-41.

86. Lurain NS, Chou S. Antiviral drug resistance of human cytomegalovirus. Clin Microbiol Rev. 2010;23(4):689-712.

87. Komatsu TE, Pikis A, Naeger LK, Harrington PR. Resistance of human cytomegalovirus to ganciclovir/valganciclovir: a comprehensive review of putative resistance pathways. Antiviral Res. 2014;101:12-25.

88. Shah AM, Oster SF, Freeman WR. Viral retinitis after intravitreal triamcinolone injection in patients with predisposing medical comorbidities. Am J Ophthalmol. 2010;149(3):433-440.

89. Chang S, Weissgold DJ, Singer JA, Sobrin L. Acute retinal necrosis after intraocular triamcinolone acetonide injection. Retin Cases Brief Rep. 2010;4(4):306-308.

90. Vinores SA, Derevjanik NL, Shi A, Vinores MA, Klein DA, WhittumHudson JA. Vascular endothelial growth factor (VEGF), transforming growth factor-beta (TGFbeta), and interleukin-6 (IL-6) in experimental herpes virus retinopathy: association with inflammation and viral infection. Histol Histopathol. 2001;16(4):1061-1071.

91. Sternberg P Jr, Han DP, Yeo JH, et al. Photocoagulation to prevent retinal detachment in acute retinal necrosis. Ophthalmology. 1988; 95:1389-1393.

92. Park JJ, Pavesio C. Prophylactic laser photocoagulation for acute retinal necrosis. Does it raise more questions than answers? Br J Ophthalmol. 2008;92:1161-1162.

93. Han DP, Lewis H, Williams GA, Mieler WF, Abrams GW, Aaberg TM. Laser photocoagulation in the acute retinal necrosis syndrome. Arch Ophthalmol. 1987;105:1051-1054.

94. Hillenkamp J, Nölle B, Bruns C, Rautenberg P, Fickenscher H, Roider J. Acute retinal necrosis: clinical features, early vitrectomy, and outcomes. Ophthalmology. 2009;116:1971e-1975e.

95. Blumenkranz M, Clarkson J, Culbertson WW, Flynn HW, Lewis ML, Young GM. Visual results and complications in the acute retinal necrosis syndrome. Retina. 1989;9:170-174.

96. Ishida T, Sugamoto Y, Sugita S, Mochizuki M. Prophylactic vitrectomy for acute retinal necrosis. Jpn J Ophthalmol. 2009;53:486-489.
Clinical Ophthalmology

\section{Publish your work in this journal}

Clinical Ophthalmology is an international, peer-reviewed journal covering all subspecialties within ophthalmology. Key topics include: Optometry; Visual science; Pharmacology and drug therapy in eye diseases; Basic Sciences; Primary and Secondary eye care; Patient Safety and Quality of Care Improvements. This journal is indexed on Submit your manuscript here: http://www.dovepress.com/clinical-ophthalmology-journal
Dovepress

PubMed Central and CAS, and is the official journal of The Society of Clinical Ophthalmology (SCO). The manuscript management system is completely online and includes a very quick and fair peer-review system, which is all easy to use. Visit http://www.dovepress.com/ testimonials.php to read real quotes from published authors. 